\title{
Reforma agrária, agroecologia e os desafios para a construção de novas formas de relação sociedade natureza durante e pós- pandemia
}

\author{
Fernanda Aparecida Matheus ${ }^{1}$ \\ Carlos Alberto Feliciano ${ }^{2}$
}

\begin{abstract}
Resumo: O presente artigo se propõe a debater as interações entre campo-cidade correlacionado questões ligadas ao surgimento e disseminação da Covid-19 e o sistema alimentar baseada no agronegócio e em contraposição o papel e os desafios da reforma agrária, dos assentamentos e da agroecologia diante da crise sanitária e socioeconômica decorrentes. Sua elaboração se deu a partir das reflexões instigadas pelas ações de solidariedade e de articulação entre camponeses e trabalhadores(as) urbanos promovidas pelos movimentos sociais durante a pandemia, e pelos trabalhos de campo realizados no âmbito do projeto de pesquisa de doutorado desenvolvido no programa de pós-graduação em geografia da Faculdade de Ciências e Tecnologia da Universidade Estadual Paulista "Júlio de Mesquita Filho" - FCT/UNESP, sobre as experiências de circuitos curtos de comercialização em áreas de assentamentos no estado de São Paulo, como ferramentas de diálogo e articulação com o meio urbano e de acúmulo de forças para promover processos de espacialização e territorialização da reforma agrária popular e da agroecologia. Desta forma, busca-se o diálogo no sentido de construir uma fundamentação teórico-conceitual sobre a importância da reforma agrária e da agroecologia para a promoção do direito humano à alimentação, à saúde e a qualidade de vida em sua totalidade, nas cidades, nas comunidades rurais e de povos tradicionais e a necessidade de se construir para tal, canais de solidariedade, articulação e alianças entre os diversos segmentos da classe trabalhadora em escala local, nacional e internacional a fim de romper com lógica do capital como fundamento para a organização e reprodução da vida e promover um sistema alimentar em bases social, econômica e ambiental, responsáveis e democráticas.
\end{abstract}

Palavras-chave: Sociedade. Natureza. Pandemia. Reforma Agrária. Agroecologia.

\section{Agrarian ReForm, Agroecology AND THE CHALlenges FOR BUILDING NeW FORMS OF SOCIETY- NATURE RELATIONSHIP DURING AND POST-PANDEMIC}

AbstraCt: The following article proposes to debate the countryside-city interections correlacting questions related to the begining of Covid-19 dissemination and the food system based on agribusiness against the role and chalenges of land reform, of settlements and agroecology in face of sanitary and socialeconomic crise. Its elaboration came trhough reflections instigated by soliday actions and articulation between peasents and urban workers promoted by social moviments during the pandemy, and field work performed in the doctorship research scope developed in geography post-degree program of Faculdade de Ciências e Tecnologia da Universidade Estadual Paulista "Júlio de Mesquita Filho" - FCT/UNESP, about the experience of commercialization shorts circuit in settlement areas on São Paulo state, as a dialog tool and articulation

\footnotetext{
${ }^{1}$ Eng. Agrônoma - UFRRJ. Especialista em Estudos Latino-americanos e Caribe - UFJF/ENFF. Mestre em Desenvolvimento Territorial na América Latina e Caribe - UNESP-IPPRI/ENFF. Doutoranda em Geografia - UNESP-FCT. Militante do MST.. E-mail: fernanda.matheus@unesp.br

${ }^{2}$ Pesquisador III do Departamento de Geografia - UNESP - Presidente Prudente. Prof. credenciado no Programa de Pós-Graduação em Geografia - UNESP e no Programa de Pós-Graduação em Desenvolvimento Territorial na América Latina e Caribe - UNESP. E-mail: cacafeliciano@gmail.com
} 
with the urban environment and the accumulation of forces to promote the processes of espacialization and territorialization of popular land reform and agroecology.

KeYwORDS: Society. Nature. Pandemy. Land Reform. Agroecology.

\section{INTRODUÇÃo}

O debate aqui proposto se insere no contexto das reflexões no período da pandemia da Covid-19, na tentativa de compreendê-la para além dos aspectos das consequências sanitárias, sociais, econômicas, culturais e emocionais, mas também a partir do questionamento das causalidades da disseminação do Sars-CoV-2, o novo Coronavírus causador da Covid-19 (WALLACE, 2020). Buscando relacionar as causas e as consequências da pandemia com o sistema alimentar hegemônico na atualidade e analisar como a práxis política, organizativa e produtiva da classe trabalhadora contribuem para a construção de metodologias e instrumentos para seu enfrentamento e superação.

A abordagem adotada parte da compreensão da doença como um fenômeno socioeconômico diretamente relacionado com a forma de organização e reprodução da vida baseada na lógica do capital (BOMBARDI, 2020). Assim, as causas e as consequências da Covid-19 devem ser analisadas no âmbito das políticas de ajuste estrutural, que provoca desemprego e precarização das condições de trabalho, retirada de direitos sociais e cortes em investimentos socais, como saúde, saneamento básico, habitação e educação e submete as populações a um sistema alimentar baseado em uma agricultura degradante em termos sociais, econômicos, culturais e ambientais (WALLACE, 2020).

No tocante as razões para o surgimento e disseminação do Sars-CoV-2, pode-se identificar intersecções com o sistema alimentar, baseado na lógica do modelo de agricultura industrial, expresso no agronegócio. Para Wallace (2020, p. 527) "esses surtos, contudo, não são apenas resultado de má sorte. Todos estão ligados, direta ou indiretamente, às mudanças na produção ou no uso do solo associadas à agricultura intensiva”.

Levando em consideração, que a pandemia da Covid-19, pode ser apenas um dentre outros possíveis surtos pandêmicos, resultantes da dinâmica de uso dos solos e recursos naturais desde a lógica do agronegócio.

O Sars-CoV-2, o novo coronavírus, causador da pandemia de covid-19 que tem atravessado o mundo, representa apenas uma das novas cepas de patógenos que subitamente surgiram como ameaças aos seres humanos neste século. Entre elas estão o vírus da peste suína africana, a Campylobacter, o Cryptosporidium, o 
Cyclospora, os ebolas Makona e Reston, a bactéria Escherichia coli O157:H7, a febre afosa, a hepatite E, a listéria, o vírus Nipah, o Coxiella burnetii da febre Q, a salmonela, o vibrião, a yersínia e algumas novas variantes do influenza a, como h1n1 (2009), h1n2v, h3n2v, h5n1, h5n2, h5nx, h6n1, h7n1, h7n3, h7n7, h7n9 e h9n2 (WALLACE, 2020, p.527).

Faz-se imprescindível, não apenas conhecer e discutir as causas e consequências do surgimento e proliferação de patógenos que podem afetar diretamente a saúde humana e a disseminação das doenças infecciosas, mas também observar e propor ideias, práticas e metodologias construídas desde a organização da classe trabalhadora no sentido de reivindicar e (re)inventar novas dinâmicas de sociabilidade entre os seres humanos e de relações sociedade-natureza baseadas na cooperação, no conhecimento, reconhecimento e respeito aos limites da natureza, na democratização do saber, dos meios de produção e do acesso aos bens comuns (HOUTART, 2011; MÉSZÁROS, 2007). A nosso ver dentre essas práticas podemos incluir a reforma agrária e a agroecologia.

Desta forma, este artigo busca dialogar no sentido de construir uma fundamentação teórico-conceitual sobre a importância da reforma agrária e da agroecologia para a promoção do direito humano à alimentação, à saúde e a qualidade de vida em sua totalidade, nas cidades, nas comunidades rurais e de povos tradicionais. Para tanto, faz-se necessário se construir canais de solidariedade, articulação e alianças entre os diversos segmentos da classe trabalhadora em escala local, nacional e internacional a fim de romper com lógica do capital como fundamento para a organização e reprodução da vida e promover um sistema alimentar em bases: social, econômica e ambiental, responsáveis e democráticas.

Sua elaboração se deu com base na revisão de literatura discutindo pandemia, sistema alimentar, agronegócio, reforma agrária e agroecologia, na análise de notas e resultados de entrevistas realizadas em março de 2020, durante o Encontro Nacional de Mulheres do MST, como parte do trabalho de campo para a elaboração da tese do doutorado em geografia desenvolvido na Universidade Estadual Paulista "Júlio de Mesquita Filho" Faculdade de Ciências e Tecnologias - UNESP/FCT sobre a relação entre o desenvolvimento de praticas de circuitos curtos de comercialização em áreas de assentamentos no estado de São Paulo e a espacialização e a territorialização da reforma agrária popular e da agroecologia e na sistematização das ações desenvolvidas pelos movimentos sociais do campo e aliados durante a pandemia buscando minimizar seus impactos e denunciar o modelo de produção do agronegócio, sobre o qual se sustenta o sistema alimentar vigente. 
A insustentabilidade do modo CAPitalista de PROduÇão Na AgriCULTURA: CONSEQUÊNCIAS PARA A VIDA PLANETÁRIA E AS RELAÇÕES COM A PROLIFERAÇÃo E DISSEMINAÇÃO DE EPIDEMIAS

Para Mészáros (2007) o capitalismo quanto sistema organizador da produção e reprodução da vida não é apenas insustentável, como também tende a autodestruição. Isso em decorrência de uma racionalidade científica, tecnológica, de produção e consumo que não leva em consideração os limites da natureza. Na agricultura, segundo Altieri e Nicholls (2020) essa abordagem, que os autores denominam de agricultura industrial, busca contornar as limitações da natureza para a produção agrícola, através do uso intensivo de adubos sintéticos e agrotóxicos. E mais recentemente com a introdução da biotecnologia e da transgenia.

Essa forma de fazer a agricultura - a agricultura industrial compõe o quadro de relações ecológicas, sociais, econômicas e éticas que sustentam se constituem no agronegócio. De acordo com Fernandes (2007) é um modelo de desenvolvimento econômico, em conformidade com os princípios do capitalismo, que apesar de suas transformações e adaptações históricas, tem suas raízes no sistema colonial de exploração.

Agronegócio é, portanto, o novo nome do modelo de desenvolvimento econômico desse conjunto de sistemas que contém, inclusive a agropecuária capitalista. Esse modelo não é novo, sua origem está no sistema plantation, em que grandes propriedades são utilizadas na produção para exportação. Desde os princípios do capitalismo em suas diferentes fases esse modelo passou por modificações, ampliações e adaptações, intensificando a exploração da terra e do homem (FERNNADES, 2007, p. 89).

Segundo Szmrecsányi (2007) o agronegócio no Brasil é uma entidade que possui raízes históricas econômicas e sociais que sustenta e é sustentada por uma estrutura de poder político que tomou novos contornos mediante a aliança entre o latifúndio e o capital mercantil e financeiro internacional. Afirma o autor que o agronegócio "configura uma aliança entre o latifúndio nacional, comandado por uma burguesia agrária e colonial, com o capital mercantil e financeiro internacional das tradings, dos operadores de bolsas de mercadorias, dos especuladores em commodities" (SZMRECSÁNYI, 2007, p. 149).

De acordo com explanações durante as plenárias de debate no Encontro Nacional de Mulheres do MST, realizado entre os dias 5 e 9 de março de 2020, em Brasília, o agronegócio reflete as mudanças no padrão de dominação capitalista pela aplicação radical das medidas neoliberais no campo, ampliando a exploração sobre o trabalho e a natureza e a expropriação dos povos de suas terras, bens da 
natureza e cultura. Trata-se de um processo com raízes históricas, econômicas e políticas, que se sustenta na aliança de classe em defesa dos interesses do capital, que mantém estritas relações com o poder político e o Estado.

A disputa do agronegócio pelo controle do Estado no Brasil é evidenciada com o processo de golpe em 2016, que não só acelera como acentua a característica de produção de commodities, retoma o histórico processo de escravidão, degradação e espoliação ambiental e amplia o processo de proletarização e expropriação dos trabalhadores. Para tal a ação estatal é orquestrada por meio de diferentes campos de ação: uso da violência e do aparato de repressão, concessões de subsídios diretos e indiretos, salvaguardas legislativas e jurídicas. Neste contexto pode-se observar a Lei 13.465/2017, que dispõe sobre os processos de titulação dos assentamentos e regularização de áreas até 2.500 há na Amazônia Legal (MATHEUS, 2020).

Segundo Thomaz Júnior (2006) o agronegócio se insere no processo de reestruturação produtiva do capital, orientada pelas políticas neoliberais propaladas pelo Banco Mundial - BM, Fundo Monetário Internacional - FMI e Organização Mundial do Comércio - OMC.

Nos campos esses fundamentos se expressam em nível mundial de forma também contundente e diferenciada, todavia governados pelo modelo agroexportador dos grandes conglomerados agroalimentares, vinculado aos programas de ajustes estruturais do Banco Mundial (BM), do Fundo Monetário Internacional (FMI), e do regime de livre comércio da Organização Mundial do Comércio (OMC) (THOMAZ JÚNIOR, 2006, p. 137).

Ramos Filho (2018) caracteriza o agronegócio como um modelo que integra diversos sistemas capitalistas, cujo principal objetivo é a ampliação da extração da mais-valia, onde envolve a produção de matérias-primas, ciência, tecnologia e aspectos envolvidos na circulação de mercadoria e reprodução do capital.

[...] modelo do agronegócio, complexo de sistemas capitalistas oligopolizados que inclui a produção agropecuária, indústria, logística, transporte, mercados, finanças, ciência e tecnologia, publicidade e propaganda. Cuja expansão se dá, tanto pela ampliação da incorporação de terras ao sistema produtivo que permita a extração de mais valia, bem como subordinando as relações sociais, o trabalho familiar e a produção realizadas(os) pelos camponeses (RAMOS FILHO, 2018, p. 42).

Para Thomaz Júnior (2006) o capitalismo se propõe como um modelo único e busca a homogeneização do modo de produzir, de consumir, de viver, de pensamento 
e de relações entre seres humanos e deste com a natureza. Entretanto esse processo encerra contradições.

Esse processo revela os seguintes traços comuns: renovação intensa da miséria rural e da miséria urbana, considerando que as pesquisas mostram as correntes migratórias de camponeses desterrados para os centros urbanos, e a manutenção da concentração da estrutura fundiária (THOMAZ JÚNIOR, 2006, p.142-143).

No tocante à questão alimentar o agronegócio substitui a produção de alimentos em sistemas de policulturas pelas extensivas monoculturas de commodities para exportação (SZMRECSÁNYI, 2007).

Os impactos provocados na saúde humana e aos agroecossistemas são derivados desse modelo do agronegócio baseado no monocultivo que ocasiona: baixa diversidade ecológica; homogeneidade genética e consequentemente vulnerabilidade do sistema com a ocorrência de infestação de plantas espontâneas, insetos e fitopatógenos que causam danos econômicos, disseminação de epidemias e doenças, morte de polinizadores, inimigos naturais e outras espécies que contribuem para a decomposição da matéria orgânica, disponibilização e assimilação da água e nutrientes e mudanças climáticas (ALTIERI; NICHOLLS, 2020).

A simplificação da dieta alimentar humana também é aspecto que sofre perdas pela diminuição da diversidade de espécies utilizadas pelos seres humanos na alimentação. Segundo Altieri e Nicholls (2020) os seres humanos poderiam se alimentar de um universo de 2.500 espécies de vegetais diferentes, entretanto, a dieta da grande maioria da população está baseada em 3 espécies cultivadas industrialmente: trigo, arroz e milho, que fornecem $50 \%$ das calorias consumidas mundialmente. Além de problemas nutricionais na população, o sistema alimentar do agronegócio apresenta baixa sustentabilidade em termos econômicos, culturais e ecológicos.

Nesta perspectiva propomos a análise e compreensão do surgimento e proliferação de epidemias, desde uma abordagem que procura averiguar as razões pelas quais microrganismos comumente encontrados na natureza em animais selvagens ultrapassam a barreira de espécie, passam para animais domésticos e em seguida para seres humanos, podendo a agir de forma patogênica sobre a saúde destes (SHAH, 2020).

$\mathrm{Na}$ realidade, grande parte de seus micróbios vive neles sem lhes fazer mal algum. O problema está em outra parte: com o desmatamento, a urbanização e a industrialização desenfreados, nós oferecemos a esses 
micróbios meios de chegar e se adaptar ao corpo humano (SHAH, 2020).

Para Wallace (2020) não só o surgimento de epidemias, como a transformação destas em pandemia como ocorreu com a Covid-19 se encontram no modo de produção do agronegócio, não só pelo seu caráter de degradação das condições ambientais que manteriam as populações de microrganismos em condições de equilíbrio e controle, mas também pelo seu caráter global, que ao deslocar mercadorias de um território para outro, transporta também os patógenos.

A monocultura de capital intensivo - tanto a pecuária quanto a agricultura - impulsiona o desmatamento e os empreendimentos que aumentam a taxa e o alcance taxonômico do transbordamento de patógenos: dos animais selvagens para os da pecuária e, destes, para os trabalhadores do setor. Uma vez que esses patógenos entram na cadeia alimentar, a produção pode contribuir com a seleção de variantes de patógenos de maior mortalidade, por recombinação genética e por mudanças antigênicas, ocorrida sob circunstâncias de supressão imunológica. Através do comércio global que agora caracteriza o setor, as cepas recém-desenvolvidas podem ser exportadas para o mundo todo (WALLACE, 2020, p. 527).

Por estas razoes, os surtos têm sido cada vez mais frequentes e abrangentes tanto em termos de escala geográfica, quanto temporal, devido à "geografias relacionais globais". "O que antes se encerrava na escala local agora se torna, de repente, uma epidemia - algumas capazes de alcançar redes globais de viagens e comércio" (WALLACE, 2020, p. 529).

Esse novo contexto é reproduzido de modos diversos de acordo com cada região. Apesar de diferentes em suas particularidades, os circuitos locais de produção operam por meio da mesma rede de expropriação global, com impactos ambientais subjacentes. Em um extremo do circuito de produção, a complexidade de florestas primárias encerra patógenos "selvagens". A exploração madeireira, a mineração e a agricultura intensiva dirigidas pelo capital simplificam drasticamente essa complexidade natural. Nessas "fronteiras neoliberais", enquanto diversos patógenos morrem como resultado do desaparecimento de espécies de hospedeiros, um subconjunto de infecções que antes era interrompido de forma relativamente rápida nas florestas, mesmo que apenas em função da taxa irregular de hospedeiros típicos disponíveis, agora se propaga com maior amplitude entre populações suscetíveis (WALLACE, 2020, p. 529). 
Para Harvey (2020) o capital na busca das condições para sua reprodução, age sobre o ambiente modificando-o e produzindo desequilíbrios que são a base para os desastres ambientais e surgimento de ameaças a vida, como é o caso da proliferação e disseminação de patógenos.

O capital modifica as condições ambientais de sua própria reprodução, mas o faz num contexto de consequências não intencionais (como as mudanças climáticas) e contra as forças evolutivas autônomas e independentes que estão perpetuamente remodelando as condições ambientais. Deste ponto de vista, não existe um verdadeiro desastre natural. Os vírus mudam o tempo todo. Mas as circunstâncias nas quais uma mutação se torna uma ameaça à vida dependem das ações humanas (HARVEY, 2020, p. 15).

De acordo com Bombardi (2020) e Shah (2020) a destruição dos habitats naturais com o avanço da agricultura e da pecuária sobre os redutos de matas primárias, são as causas para a proliferação e disseminação de doenças. Segundo as autoras as matas são áreas sensíveis e com complexas de relações entre seres vivos e funcionam como barreiras biológicas para controle da proliferação de organismos patogênicos e vetores. Logo, quando se rompe estas barreiras, é possível que organismos patogênicos saltem para comunidades humanas e/ou se criem condições para o desenvolvimento ou deslocamento de vetores transmissores de doenças para áreas urbanas, como o caso da febre amarela.

Em ecossistemas equilibrados, os processos são lentos e existem no sistema inúmeros organismos que se controlam mutuamente, quando se retira a vegetação natural e a perda de diversas espécies vegetais e animais, organismos patogênicos podem se proliferar e disseminar rapidamente e atingir animais domésticos. E isto ocorre de forma mais intensa animais em confinamento, com sistema imunológico fragilizado (SHAH, 2020; BOMBARDI, 2020).

Para Shah (2020) os criatórios de animais em sistema industrial se assemelham a fábricas de animais, com suas linhas de montagem, alocadas em espaços reduzidos, exigem homogeneidade e uniformidade da matéria-prima. Afirma a autora "centenas de milhares de animais amontoados uns sobre os outros, à espera de ir para o matadouro: eis as condições ideais para que os micróbios se transformem em agentes patogênicos mortais" (SHAH, 2020).

Essas circunstâncias associadas ao intensivo uso de antibióticos, por vezes agravadas pelo confinamento dos animais em instalações, onde são mantidos em contato com dejetos, criam condições para que um patogênico ao atingir um plantel, se espalha rapidamente, não havendo tempo para se produzir uma resposta imunológica. 
En la cadena agroindustrial, mantener con salud al ganado es una industria gigantesca. Las ventas globales de productos de farmacéutica animal ascienden a 23 mil 900 millones de dólares anuales y sólo 10 empresas controlan $83 \%$ del mercado. 75 No obstante, $60 \%$ de todas las enfermedades infecciosas humanas son transmitidas por animales con uniformidad genética extrema, domesticados para la producción masiva de carne y derivados (como la gripe aviar). En vez de criar y reproducir especies y variedades animales para la diversidad y la resistencia, hay campañas para eliminar las razas indígenas de pollos y cerdos para mantener la uniformidad genética de las variedades comerciales. Corporaciones estadounidenses y coreanas comenzaron a clonar ganado y una empresa chino-coreana propone enviar a China, por año, 100 mil cabezas de ganado clonado. A pesar de algunas prohibiciones, los antibióticos se siguen aplicando al ganado como promotores del crecimiento. Aunque algunos gobiernos prometieron eliminar tales abusos, su uso aumentó 23\% en Estados Unidos entre 2009 y 2014.79 La resistencia a los antibióticos cuesta anualmente 55 mil millones de dólares a la economía estadounidense.80 Ahora, cuando tal vez ya sea muy tarde, los gobiernos del mundo reconocen que la resistencia a los antibióticos constituye una amenaza a la humanidad quizá similar a la del cambio climático (ETC GROUP, 2017, p.24, grifo do autor).

Todo esse histórico de catástrofes ambientais, crise climática, social, econômica sanitária e ética não diz nada ao capital e sua atuação no campo, que ao invés de modificar suas práticas predatórias e degradantes, durante a pandemia as tem intensificado. Bem como tem visto aumentado seus lucros.

Em matéria publicada, em 20 de outubro de 2020, na coluna Agronegócios do Valor Econômico foi anunciado a inauguração de uma nova unidade de confinamento em Confressa-MT, pela empresa Friboi - grupo JBS, para este ano, com capacidade de engordar $12 \mathrm{mil}$ animais ao ano. A mesma reportagem informa que outras duas unidades foram inauguradas em 2020, cada uma destas, com capacidade de engorda de 10 mil animais anualmente. Com os investimentos realizados em 2020, a empresa contabiliza 8 unidades distribuídas nos estados de São Paulo, Mato Grosso, Mato Grosso do Sul e Minas Gerais, que juntas tem capacidade de engorda de 116 mil animais/ano.

A pecuária, juntamente com a produção de soja, cana-de-açúcar, a celulose tem promovido a ampliação da fronteira agrícola, avançando sobre áreas até então com vegetação nativa e populações tradicionais. Esse processo tem ocorrido por meio de grilagem de terras públicas e devolutas, invasão de terras indígenas, desmatamento e queimadas. Entretanto, a agricultura e a pecuária não são os únicos responsáveis 
por alimentar, a mineração e a produção de energia também integram esse histórico processo de devastação socioambiental.

Todo esse processo faz parte da dinâmica de reprodução do capital e conta com a atuação de empresas nacionais e transnacionais como a Vale, Anglo American, Potássio do Brasil, Cargill, JBS, Cosan/Raízen, Bom Futuro Energia, Eletronorte. E compõe o rol de investimentos internacionais com participação de corporações financeiras, dentre as quais: a Blackrock - a maior gestora de ativos do mundo, a Citigroup, JP Morgan Chase, Vanguard e Bank of America (APIB; AMAZON WATCH, 2020). É a materialização da aliança entre o agronegócio, os interesses do latifúndio e o capital transnacional.

Figura 1 - Série histórica de focos de queimadas por bioma e ano no Brasil.

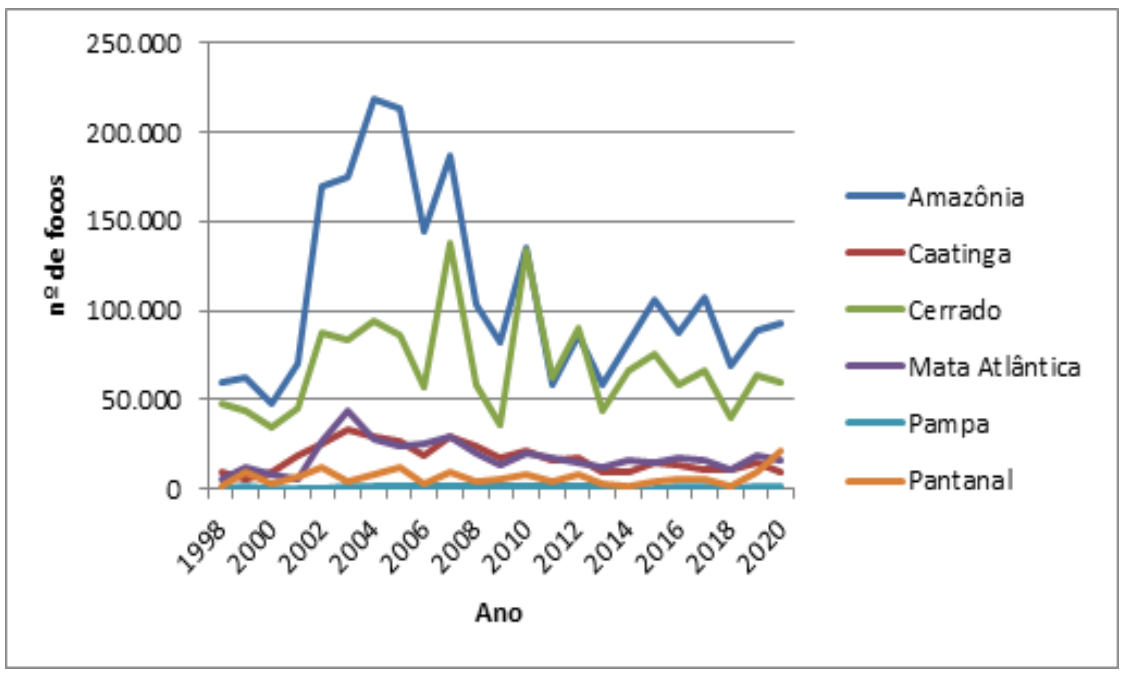

Fonte: Instituto Nacional de Pesquisas Espaciais (2020).

Com base nos dados da série histórica de focos de queimadas no Brasil, organizada pelo Instituo Nacional de Pesquisas Espaciais (INPE) desde 1985, ilustrados no gráfico a seguir, podemos observar que o problema com as queimadas é um crime constante que atinge os biomas brasileiros, com maior incidência ao longo do tempo sobre a Amazônia e o Cerrado. Mas com ocorrências expressivas também na Mata Atlântica, Caatinga e Pantanal. O gráfico demonstra os primeiros anos do século XXI como o auge da incidência de focos de incêndios sobre os biomas de modo geral. Com relação à Mata Atlântica e à Caatinga, observa-se uma tendência a queda das ocorrências, desde os anos 2000 até o presente momento; o inverso pode ser observado com relação ao Pantanal, que nos últimos 2 anos sofreu um 
aumento expressivo dos focos de queimadas.

De acordo com levantamento do Observatório do Agronegócio no Brasil "DE OLHO NOS RURALISTAS", a partir da lista de multados pelo IBAMA, o perfil dos maiores desmatadores do Pantanal nos últimos 25 anos é composto por empresas e pessoas físicas, que atuam em diversos ramos da economia, são políticos e empresários influentes, proprietários de terras em várias regiões dentro e fora país e ostentam um extenso histórico de crimes ambientais e violações de direitos das populações tradicionais (FUHRMANN, 2020a).

Segundo reportagem publicada pelo jornal Brasil de Fato (online), em 28 de outubro de 2020, a pecuária, a siderurgia, a cana-de-açúcar, a soja lideram o ranking de desmatamentos no Pantanal (FUHRMANN, 2020b). Na figura a seguir pode-se observar uma relação das 15 empresas ou pessoas físicas que receberam o maior número de multas por desmatamento no Pantanal desde $1995^{3}$.

Figura 2 - Os maiores multados no Pantanal desde 1995.

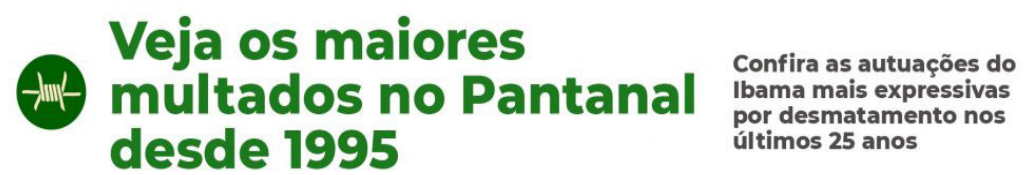

\begin{tabular}{|c|c|c|c|}
\hline MUNICÍPIO & EMPRESA & DATA & MULTA (R\$) \\
\hline Corumbá - MS & Brpec Agropecuária S/A & $12 / 05 / 2018$ & 57.999 .500 \\
\hline Corumbá - MS & Mmx Metálicos Corumbá Ltda & $06 / 06 / 2008$ & 15.225 .390 \\
\hline Aquidauana - MS & Renato Alves Ribeiro & $12 / 14 / 2016$ & 13.970 .000 \\
\hline Barão de Melgaço - MT & Raul Amaral Campos & $07 / 21 / 2011$ & 11.030 .000 \\
\hline Coxim - MS & Roberto Pedro Tonial & $08 / 23 / 2010$ & 10.015 .000 \\
\hline Aquidauana - MS & Simasul Siderurgia Ltda & $06 / 07 / 2008$ & 9.498 .880 \\
\hline Corumbá - MS & Reginaldo Farias Santos & $08 / 05 / 2013$ & 9.064 .800 \\
\hline Itiquira - MT & Fazenda Ribeirao Agropecuária Ltda & $02 / 13 / 2019$ & 8.000 .000 \\
\hline Miranda - MS & Black Ind. Imp. Expo. E Comércio De Carvão Vegetal Ltda - Me & $02 / 13 / 2013$ & 7.380 .000 \\
\hline Aquidauana - MS & Jose Maia Costa & $10 / 29 / 2018$ & 7.310 .000 \\
\hline Porto Murtinho - MS & Silvio Eduardo Burani & $03 / 09 / 2012$ & 6.699 .000 \\
\hline Rio Verde de Mato Grosso - MS & Eurydes Beretta Júnior & $08 / 14 / 2018$ & 6.610 .000 \\
\hline Porto Murtinho - MS & Agropecuaria Santa Mariana Ltda & $04 / 17 / 2013$ & 6.560 .000 \\
\hline Poconé - MT & Oswaldo Cid Nunes Da Cunha & $09 / 28 / 2000$ & 6.000 .000 \\
\hline Corumbá - MS & Geraldo Albanez & $09 / 19 / 2001$ & 6.000 .000 \\
\hline \multicolumn{4}{|c|}{ Fonte: Ibama/ De Olho nos Ruralistas } \\
\hline
\end{tabular}

Fonte: DE OLHO NOS RURALISTAS (2020).

Os elementos sobre os quais discorremos anteriormente embasam a consideração

\footnotetext{
${ }^{3}$ A lista completa com 58 autuados pode ser acessada em: https://www.brasildefato.com.br/2020/10/28/gado-carvao-canae-soja-estao-por-tras-do-desmatamento-milionario-no-pantanal.
} 
de que o sistema alimentar, entendido como processo que envolve a produção, circulação e consumo de alimentos, abrangendo as dimensões sociais, econômicas, políticas, ambientais, tecnológicas e éticas na atualidade não tem como fundamento o atendimento das necessidades vitais e o bem comum da sociedade (HOUTART, 2011), mas sim a produção do lucro.

Assim as consequências sociais, econômicas, culturais e sanitárias provocadas pelo sistema alimentar do agronegócio afeta toda a sociedade com efeitos diretos sobre a saúde. O desmatamento e as queimadas e o uso de fertilizantes sintéticos e agrotóxicos destroem a biodiversidade e cria as condições para a proliferação vetores transmissores e patógenos que causam doenças (BOMBARDI, 2020). Esse processo expulsa populações do campo e as amontoa nas periferias dos centros urbanos onde vivem em precárias condições sanitárias, de moradia, de trabalho e de alimentação, o que por sua vez também produz efeitos sobre a saúde humana (ALENTEJANO, 2020). E a lógica de territorialização da produção em busca de melhores condições para a extração da mais-valia, exige longos circuitos para a comercialização de alimentos que requerem constantes deslocamentos de mercadorias e pessoas através dos territórios, que podem servir para transportar patógenos de um território ao outro.

A reforma agrária e a agroecologia frente aos desafios de INTERROMPER O CICLO DE DEVASTAÇÃO SOCIOAMBIENTAL E CONSTRUIR UM SISTEMA ALIMENTAR DEMOCRÁTICO, JUSTO E SUSTENTÁVEL

$\mathrm{O}$ avanço do agronegócio aumentou as disputas pela terra, pelos bens da natureza no e pelos territórios, exigindo uma ressignificação das lutas no campo. Está é uma síntese da análise realizada pelas mulheres militantes do MST, durante seu Encontro Nacional, realizado em março de 2020 (MATHEUS, 2020). Tal análise se insere no contexto do debate da reforma agrária popular pautada pelo MST e sustenta a proposição de um novo jeito de organizar o campo e a agricultura, que tem como pressuposto a democratização da terra, a garantia de direitos às populações do campo, o cuidado com os bens da natureza, a alimentação como direito humano fundamental e a produção de alimentos com base na agroecologia (MOVIMENTO DOS TRABALHADORES RURAIS SEM TERRA, 2013). Diante do exposto neste artigo, no tópico anterior um programa de reforma agrária nestes termos está diretamente relacionado a um processo de resistência e enfrentamento ao capital e concretamente propõe o rompimento com o sistema alimentar do agronegócio.

Segundo o MST a materialização do programa de reforma agrária popular passa por uma aliança da classe trabalhadora em defesa da reforma agrária e da agroecologia como fundamento de um sistema alimentar que garanta o direito 
humano a alimentação e a construção de novas relações sociedade-natureza.

A construção desse processo só será possível através de uma práxis (VÁSQUES, 2007) cotidiana, que envolve conflitos e disputas com o agronegócio e com o Estado e ações práticas concretas para garantir materialidade para além da teoria. Trata-se de aliar ação e reflexão, conciliar o fazer e o pensar em uma unidade dialética, que exige constante planejamento, sistematização e replanejamento para o aperfeiçoamento da prática.

Neste debate a terra é o elemento central e a ocupação se reafirma como ferramenta fundamental para sua democratização, que só é possível com o apoio do conjunto da classe trabalhadora, para romper com o poder político e econômico do agronegócio. Sendo assim, o diálogo com a sociedade almeja não apenas a obtenção de apoio à pauta de reivindicação por terra e território dos povos do campo, mas como pauta conjunto da classe trabalhadora para a construção de novas formas de sociabilidade e relações sociedade-natureza. Neste contexto a reforma agrária e a agroecologia se constituem em pilares para o enfrentamento ao sistema alimentar do agronegócio e a construção de um sistema alimentar baseado nos interesses e necessidades do conjunto da população e não em função da reprodução do capital.

Tal posicionamento político e teórico tem sido afirmado pelo MST e fundamenta o programa de reforma agrária, aprovado em seu VI Congresso, realizado em 2014, sintetizado pela consigna da reforma agrária popular (MOVIMENTO DOS TRABALHADORES RURAIS SEM TERRA, 2013). Entretanto, já nos primeiros anos do século XXI vários elementos que hoje compõe esta análise e embasaram a elaboração do programa agrário aprovado em 2014, foram pontuados pelo MST, como pode ser checado através palavras de ordem em seus congressos anteriores.

Em 2003 Alentejano questionava o padrão de desenvolvimento e urbanização adotado pela sociedade brasileira e apontava a reforma agrária como uma possibilidade política e econômica para atender as demandas por terra, trabalho, aceso a infraestrutura e serviços e alimentos da sociedade, além de contribuir para o processo de democratização do país.

O caráter fortemente urbanizado da sociedade brasileira deve ser o ponto de partida para a nova reflexão sobre o lugar da reforma agrária no debate sobre o modelo de desenvolvimento a ser adotado no país, mas não para negar importância à reforma agrária, mas para afirmá-la como essencial para, no curto prazo, garantir melhores condições de vida para uma imensa massa de explorados e excluídos presentes hoje no campo e na cidade e, a médio e longo prazo, possibilitar a construção de uma sociedade justa e democrática (ALENTEJANO, 2003, p. 27). 
De acordo com Alentejano (2003, p.36) reforma agrária "trata-se de ampliar o número de pessoas que mora e que come, mas também que tem acesso a lazer, a cultura e a participação política”.

Ainda segundo a formulação do autor.

Portanto, a solução para a crise que se abate sobre as cidades brasileiras e o caminho para construir uma sociedade mais justa e democrática passam pelo aproveitamento do imenso estoque de terras inaproveitadas e mal aproveitadas pelos latifundiários brasileiros (e estrangeiros) para o assentamento massivo de trabalhadores rurais e urbanos, oferecendo a estes infra-estrutura adequada, apoio à produção agrícola e não-agrícola e condições para o livre exercício de sua cidadania. Isto seria o princípio de um processo de revolução da nossa organização social e territorial (ALENTEJANO, 2003, p. 38).

Em 2020 frente à pandemia da Covid-19 o autor retoma a construção teórica da reforma agrária como instrumento de combate ao desemprego e à miséria nas metrópoles, possibilitando moradia, trabalho e dignidade as populações pobres nos centros urbanos, acrescentando aspectos do debate ambiental. Escreve Alentejano (2020, p.33) “ [...] a contribuição que a reforma agrária poderia dar para a reorganização territorial da sociedade brasileira e a construção de uma sociedade mais justa, democrática e ambientalmente saudável".

Para Alentejano (2020) a luta pela reforma agrária e a construção da agroecologia envolve a disputa territorial entre o latifúndio-agronegócio e o campesinato, que apesar se ser travado no campo, tem efeitos sobre as condições de vida da população urbana e, portanto, devem se constituir em bandeira de luta da classe trabalhadora urbana. $\mathrm{O}$ autor diz que a concepção de reforma agrária que está sendo construída pelos movimentos sociais do campo em suas formulações teóricas e suas ações práticas, são a expressão de uma reforma agrária agroecológica.

A construção de uma reforma agrária agroecológica tem sido colocada como pauta pelo Movimento dos Trabalhadores Rurais Sem Terra (MST) e outros movimentos sociais do campo. Trata-se não apenas de mudar o padrão técnico dominante com a rejeição aos agrotóxicos, mas de construir outras práticas produtivas, outras formas de comercialização, outras relações de trabalho, outras relações sociedade-natureza que superem a fratura metabólica instaurada pelo capital (ALENTEJANO, 2020, p.35-36).

Altieri e Nicholls (2020) ao debater a crise sanitária diante da pandemia, realçam a relevância da agroecologia para o conjunto da sociedade, de modo especial 
para as populações urbanas. E apontam as potencialidades de uma abordagem agroecológica para construir novas abordagens e práxis, restabelecendo os vínculos entre a agricultura com a natureza, incluindo os seres humanos, cuidados com a saúde humana, como um dos componentes da saúde ambiental.

Diante de tais tendências globais, a agroecologia ganhou muita atenção nas últimas três décadas como base para a transição para uma agricultura, que não apenas proporcionaria às famílias rurais, benefícios sociais, econômicos e ambientais significativos, mas também alimentaria as massas urbanas de maneira equitativa e sustentável. Existe uma necessidade urgente de promover novos sistemas alimentares locais para garantir a produção de alimentos abundantes, saudáveis e acessíveis para uma crescente população humana urbanizada. Esse desafio será difícil, considerando os cenários previstos de uma base de terra arável em declínio; com petróleo caro e preços voláteis; suprimentos cada vez mais limitados de água e nitrogênio; e, em um momento de mudanças climáticas extremas, tensões sociais e incerteza econômica (ALTIERI; NICHOLLS, 2020).

Segundo os autores:

Não há dúvida de que o melhor sistema agrícola capaz de enfrentar desafios futuros é aquele que se baseia em princípios agroecológicos que exibem altos níveis de diversidade e resiliência, oferecendo rendimentos razoáveis e serviços ecossistêmicos. A agroecologia propõe restaurar as paisagens que circundam as propriedades rurais, o que enriquece a matriz ecológica e seus serviços, como controle natural de pragas, conservação do solo e da água, etc., mas também cria "quebra-fogos ecológicos" que podem ajudar a impedir que patógenos escapem de seus habitats (ALTIERI; NICHOLLS, 2020).

Para Petersen e Londres (2015) debates e ações empreendidas pelos movimentos sociais, governos latino-americanos e organismos internacionais nos últimos anos tem possibilitado o reconhecimento da potencialidade da agroecologia para a resolução da crise ambiental, energética, climática, alimentar e social. E reiteram a agroecologia como meio para transformações estruturais nos sistemas alimentares e não apenas como tecnologias paliativas para reduzir os impactos da agricultura industrial, que se restringe a produção destinada ao mercado de produtos orgânicos em benefício de uma pequena parcela de produtores e consumidores.

“[... ] a agroecologia deve ser compreendida como uma reação social crítica 
e ativa frente aos efeitos socioambientais negativos gerados pelo projeto de modernização agrícola implantado nos países da região a partir da década de 1960. Essa reação mobiliza também parcelas crescentes do campo científico-acadêmico envolvidas na sistematização e no desenvolvimento teórico da agroecologia. Por meio dessa evolução descentralizada, que articula atores de várias esferas sociais, a Agroecologia é hoje concebida como uma prática, como uma ciência e como um movimento social (PETERSEN; LONDRES, 2015, p. 35).

Para o MST (MATHEUS, 2020) a discussão e as práticas agroecológicas estão inseridas dentre os desafios de construir formas de permanência na terra, nos acampamentos e nos assentamentos, enfrentar os processos de despejo e de privatização dos assentamentos e afirmar a função socioambiental da terra, como bem da natureza e não como mercadoria.

A partir do debate proposto no Encontro Nacional das Mulheres do MST, interpretamos que a resistência nos territórios conquistados-acampamentos e assentamentos apresenta várias dimensões. A dimensão econômica que contempla aspectos da agregação de valor à produção, organização do beneficiamento e comercialização. A dimensão sociocultural que abrange a questão da educação e do exercício e projeção de outras formas de sociabilidade que diz respeito à participação dos sujeitos nos espaços de discussão e tomada de decisão e as relações interpessoais e respeito à diversidade.

A dimensão das relações sociedade-natureza inclui o desafio de fazer o conjunto da sociedade, compreender o caráter degradante agronegócio social, econômica e ambientalmente e a importância da reforma agrária e da agroecologia para a defesa e o cuidado com a natureza, de modo especial com a vida humana. A questão da formação tanto política quanto técnica a nosso ver perpassa pelas três dimensões, pois se refere à construção das ideias e práticas sobre a qual se sustentam.

Alentejano (2003) destacava como desafios da reforma agrária para o atendimento das necessidades das famílias diretamente beneficiadas pela distribuição de terras e para o conjunto da sociedade:

[...] o estímulo à cooperação e ao exercício da solidariedade, fazendo dos assentamentos espaços não apenas de cooperação interna na produção, mas de exercício de solidariedade em relação à população de seu entorno; a busca de um modelo de desenvolvimento sustentável, ou seja, capaz de gerar renda e alimentos suficientes para a garantia de uma boa qualidade de vida para a população, mas também de garantir a qualidade dos alimentos produzidos, a preservação (ou recuperação) ambiental, de modo que a preservação do 
ambiente seja parte do modo de vida dos assentados e contra-exemplo à tendência dominante de apropriação privada do que resta de recursos naturais preservados; a retomada do princípio de que os especuladores devem ser punidos por manterem a terra improdutiva, dados os custos que isso gera para a sociedade e a injustiça presente neste fato, tomando como base para a definição do valor pago pelas desapropriações não o valor de mercado, mas o declarado no ITR, sabidamente subestimado pelos proprietários; recolocar em pauta o confisco das terras exploradas com base em trabalho infantil, escravo e outras formas ilegais; negar a compra de terras, por seu caráter de prêmio aos especuladores e aos latifundiários; retomar o debate acerca do estabelecimento de limites máximos para o tamanho das propriedades, como base para a geração de uma melhor distribuição de riqueza e renda; recolocar o debate acerca da melhor forma de titulação da terra, negando a proposta imposta hoje de forma unilateral pelo governo de distribuição de títulos de propriedade, e afirmando o princípio da garantia da terra pública e de seu usufruto em benefício da sociedade (ALENTEJANO, 2003, p.38).

Via de regra, todos esses desafios continuam não só atuais, como também fazem parte da agenda de lutas dos movimentos sociais do campo. Inúmeras têm sido as ações concretas elaboradas e em desenvolvimento nos territórios conquistados, como o Plano Nacional: plantar árvores e produzir alimentos saudáveis. A iniciativa anunciada no início de 2020 "tem como objetivo realizar a recuperação de áreas degradadas por meio da implementação de agroflorestas e quintais produtivos" (FERREIA, 2020) e prevê o plantio pelas famílias acampadas e assentadas de 100 milhões de árvores, no período de 10 anos. De acordo com o MST outra finalidade do projeto "é denunciar as ações de destruição ambiental do agronegócio, da mineração e construir no MST e na sociedade o entendimento que Reforma Agrária é sinônimo de alimentação saudável e de cuidado com os bens comuns da natureza" (FERREIA, 2020).

Especificamente no contexto da pandemia, o MST debateu e aprovou o Plano Emergencial de Reforma Agrária Popular: por trabalho, alimentação e vida digna (GOULD, 2020). O documento foi elaborado a partir de 4 pontos básicos:

\section{A) Terra e Trabalho}

Assentamento das famílias que se encontram acampadas ou desempregadas nos centros urbanos mediante desapropriações de latifúndios improdutivos; retomada sem custos de áreas de devedores da União, destinação de terras públicas e terras devolutas, trocas das dívidas dos latifundiários aos bancos públicos, por terra; suspensão de despejos e reintegrações de posse; legalização de áreas de comunidades 
tradicionais (quilombolas, povos indígenas, ribeirinhos); garantia da integridade e a preservação de reservas indígenas e áreas ambientais, expulsando invasores, grileiros, madeireiros, garimpeiros ilegais; suspensão de subsídios e isenções fiscais às empresas de agrotóxicos.

\section{B) Produção de alimentos Saudáveis}

Destinação e ampliação de recursos ao PAA (Programa de Aquisição de Alimentos); assegurar o cumprimento do PNAE (Programa Nacional de Alimentação Escolar) durante o distanciamento social, com comida saudável para atender crianças e suas famílias; implantação do Plano nacional de agroecologia, para garantir alimentos saudáveis para a população; organização de hortas urbanas agroecológicas; usar linhas de crédito especial dos bancos públicos para financiar agroindústrias cooperativas para produção de alimentos e liberar fomento emergencial para os assentamentos.

\section{C) Proteger a natureza, a Água e a biodiversidade}

Proteger as nascentes e fontes de água, as florestas e a biodiversidade; apoiar programas de massificação do plantio de árvores nativas e frutíferas de acordo com o bioma; destinação de recursos necessários para construção de cisternas; impedir o uso dos agrotóxicos; produção de sementes agroecológicas em todos os territórios; estimular as agroflorestas.

\section{D) CONDIÇões de VIDA digna No CAMPo PARA TOdo O POVO}

Garantia de acesso para todas as famílias ao Programa "Minha casa, minha vida”, para reformas e construção de moradias no meio rural; assegurar políticas para a permanência da juventude no campo com trabalho, renda e educação; não fechamento de escolas no campo; fortalecimento do FUNDEB e ampliação do PRONERA; enfrentamento à violência doméstica e lgbtfobia no campo e ampliação e fortalecimento do SUS.

Durante a pandemia, várias tem sido as atividades articuladas pelos movimentos sociais do campo e aliados urbanos, dentre os quais o MST, no sentido de afirmar a reforma agrária e a agroecologia como pares indissociáveis, na construção de alternativas para a produção de alimentos saudáveis e a preços acessíveis para toda a sociedade. Neste contexto, as iniciativas empreendidas tentam demonstrar a possibilidade de conciliação entre a produção de alimentos, a recuperação de áreas degradadas pelo agronegócio e o cuidado com os seres humanos e os bens da natureza. E a agroecologia é reivindicada como um modo de vida e uma ferramenta para romper com todas as formas de opressão e promover mudanças 
de comportamento, seja na relação sociedade-natureza, seja na relação entre os seres humanos.

O dia 16 de outubro, em que se comemora o Dia Internacional da Alimentação, transformado pelos movimentos sociais e populares do campo, da cidade e das florestas, no Dia Internacional de Ação dos Povos e Contra as Corporações Transnacionais pela Soberania Alimentar. No ano de 2020 contou com uma série de atividades de denuncia com relação ao aumento dos preços dos alimentos e os vetos do governo federal à Lei Assis Carvalho ${ }^{4}$ - PL 735, durante a semana que intitularam de Semana Nacional da Alimentação (GIMENES, 2020), além da distribuição de alimentos e plantio de árvores em diversas localidades do país.

Segundo balanço do próprio MST, a organização havia realizado desde o início da pandemia até o dia 09 de setembro de 2020 ações de solidariedade em 24 estados do país, totalizando 3.400 toneladas de alimentos distribuídos em parceria com a Campanha Periferia Viva, constituída pelo MST, Movimento dos Pequenos Agricultores (MPA), Movimento dos Atingidos por Barragem (MAB), Levante da Juventude, Movimento de Trabalhadoras e Trabalhadores por Direitos (MTD) e Movimento Pela Soberania Popular na Mineração (MAM) e a iniciativa Vamos Precisar de Todo Mundo, composta pelas Frentes Brasil Popular e a Frente Povo Sem Medo Além da distribuição de marmitas com refeições prontas, equipamentos de proteção individual, produtos de higiene e livros, a organização de hortas comunitárias agroecológicas nas cidades (ALCÂNTARA, 2020) e a formação de agentes populares de saúde, para atuarem nos bairros onde vivem nas periferias dos centros urbanos, orientando a população para prevenção a Covid-19 (CHAGAS, 2020).

Alguns aspectos relevantes que se pode observar nestas iniciativas é a relação que estas têm com processos de organização e articulação anteriores a pandemia. Em audiovisual produzido pelo coletivo de comunicação do MST no Pontal do Paranapanema, apresenta pontos de contato entre as experiências de circuitos curtos de comercialização com as ações de solidariedade durante a pandemia. Tudo isso, com a finalidade de divulgar as ações em celebração do dia 16 de outubro (Dia Mundial da Alimentação).

As entrevistas realizadas ${ }^{5}$ pela primeira autora no âmbito do projeto de pesquisa de doutorado sobre as relações entre circuitos curtos de comercialização,

\footnotetext{
${ }^{4}$ Projeto de Lei aprovado na Câmara dos Deputados e Senado prevê apoio à agricultura familiar no contexto da pandemia e foi desfigurada pelos votos do presidente da República. Recebeu o nome Assis de Carvalho em homenagem ao deputado federal do Piauí, atuante na defesa da agricultura familiar, falecido recentemente.

${ }^{5}$ Entrevistas realizadas entre os dias 05 e 09 de março de 2020, em Brasília, durante o Encontro Nacional de Mulheres do MST, com mulheres militantes do MST, no estado de São Paulo. Foram entrevistadas mulheres (uma mulher de cada assentamento) envolvidas nos processo e organização de experiências de circuitos curtos de comercialização nos assentamentos: Dandara - município de Promissão, Fazenda Ipanema - município de Iperó, Nova Esperança - município de São José dos Campos e Carlos Lamarca - município de Sarapuí.
} 
reforma agrária popular e agroecologia também nos permitem detectar certas confluências entre os princípios que orientam estas experiências e as ações de solidariedade durante a pandemia, dentre o quais o acesso a alimentação saudável como direito humano fundamental; o contato entre produtores(as) e consumidores, em um processo de co-responsabilização de segmentos urbanos da população pela produção dos alimentos e a transformação das condições econômicas, sociais, ecológicas e éticas em que estes são produzidos; a afirmação da agroecologia como base para a produção de alimentos saudáveis; o envolvimento de segmentos urbanos da classe trabalhadora na discussão sobre reforma agrária e agroecologia e a responsabilização pela manutenção das condições de produção e resistência econômica nas áreas de assentamento diante da situação de avanço do agronegócio.

De acordo com depoimentos das entrevistas se verifica uma grande diversidade de alimentos produzidos e consumidos tanto pelas famílias produtoras quanto coprodutoras, o que segundo as entrevistadas contribui para um processo de reeducação alimentar e ambiental no campo e na cidade. Estas formas de comercialização de forma geral estão associadas a processos de formação e de articulação política e contribuem para a conformação de espaços de luta e resistência ao agronegócio, como a criação de comitês locais da campanha permanente contra os agrotóxicos (MATHEUS, 2020).

Segundo a entrevistada assentada no assentamento Dandara, município de Promissão, a participação de pessoas do meio urbano nos debates sobre reforma agrária só é possível pela demonstração dos acampamentos e assentamentos como territórios de produção de alimentos saudáveis. De acordo com o relato as experiências de circuitos curtos de comercialização têm promovido várias atividades de vivências entre produtores e coprodutores, como plantio, festa, cafés, o que permite com que a população urbana conheça os assentamentos e vejam uma realidade distinta da que aparece na mídia. De maneira complementar, a entrevistada do assentamento Fazenda Ipanema, afirma que tais práticas possibilitam às pessoas a construção do conhecimento sobre o que se está comendo e como seu alimento é produzido.

Para a entrevistada assentada no assentamento Carlos Lamarca, município de Sarapuí a comercialização através dos circuitos curtos de comercialização a importância está para além das questões econômicas "não é nem pela renda, mas pelo contato, por estar mostrando os produtos nestes espaços, aí se tem uma relação muito boa, é a barraca da conversa, da divulgação e da troca de sementes".

A entrevistada assentada no assentamento Nova Esperança, município de São José dos Campos afirma que "Se não fosse a contribuição da CSA (Comunidade que

Sustenta a Agricultura $)^{6}$ não conseguiríamos fazer a produção agroecológica.

${ }^{6}$ Modalidade de circuito curto de comercialização baseado no princípio de coparticipação dos consumidores no processo de produção dos alimentos. Para isso, os coprodutores estabelecem um sistema de cotas para custear os custos de produção 
Nossa luta é pela agroecologia, no sentido do cuidado do organismo agrícola, a agricultura orgânica, somente propõe a substituição de insumos”. Para a entrevistada que destaca como desafio para a produção agroecológica e os circuitos de comercialização se expandir para as periferias "às vezes o primeiro contato é impactante para quem não conhece o MST, mas depois começam a compreender e admirar o MST".

A partir do relatado podemos concluir que há características e princípios comuns entre as práticas dos circuitos curtos de comercialização e a articulação das ações de solidariedade realizadas durante a pandemia. É possível que esta modalidade de comercialização possa ter contribuído para a articulação das ações de solidariedade, assim como é possível que as ações de solidariedade venham a contribuir para ampliar das experiências de comercialização. Mas certamente o que está posto é o desafio da continuidade e ampliação das alianças entre movimentos e sociais e populações do campo, da cidade e das florestas em defesa da reforma agrária e da agroecologia, como fundamento para alcançar melhores condições de vida no campo, nas cidades e nas florestas.

\section{Conclusões}

As ações realizadas pelos movimentos sociais e populares do campo, da cidade e das florestas, no contexto da pandemia expressam um processo de articulação e estabelecimento de alianças entre estas organizações que diante da situação de calamidade e ausência do poder público exercitam formas de relações humanas baseadas na solidariedade, da cooperação, no atendimento as necessidades básicas da população e do cuidado com a vida.

São práticas que convidam a população a refletir sobre a importância de um processo de reforma agraria como instrumento para alcançar melhorias nas condições no campo e na cidade, principalmente no que se refere ao acesso a alimentos e as condições de produção de alimentos (qualidade, diversidade, preço, quem os produz, onde e como). Ou seja, estas ações podem vir a se constituir em importantes meios para se questionar o sistema alimentar do agronegócio e suas consequências para a saúde e a vida no planeta e produzir elementos para pensar outro modo de produzir e consumir desde os interesses e necessidades da classe trabalhadora.

Estas práticas se relacionam os cuidados com a saúde humana e da natureza em sua totalidade. Entende as doenças e propõe o tratamento não só a partir de cuidados pontuais, paliativos e curativos, mas procuram relacionar suas causas em fatores econômicos, sociais e ambientais. Neste sentido essas práticas denunciam a destrutividade das políticas neoliberais e do agronegócio, assim como seu sistema

e manutenção da família de produtores de alimentos. 
alimentar, como responsáveis pela proliferação e disseminação da pandemia da Covid-19 e outras possíveis epidemias futuras.

As ações articuladas pelos movimentos sociais tanto internamente em seus territórios ou externamente conjuntamente com grupos e organizações urbanas durante a pandemia e anteriormente, no sentido de denunciar os efeitos negativos do sistema alimentar do agronegócio e de propor a discussão da reforma agrária e da agroecologia como alternativas são fundamentais para a construção de formas de organização e reprodução da vida, fundamentadas na solidariedade, na cooperação, na promoção do bem comum e no cuidado e respeito à vida humana e a natureza. São sementes que carregam possibilidades de novas relações sociedade-natureza.

\section{REFERÊNCIAS}

ALCÂNTARA, F. Desde o início da pandemia, MST já doou 3.400 toneladas de alimentos. Movimento dos Trabalhadores Rurais Sem Terra, 9 set. 2020. Disponível em:< https://mst.org.br/2020/09/09/desde-o-inicio-da-pandemia-mst-ja-doou-3400-toneladas-de-alimentos/>. Acesso em: 28 out. 2020.

ALENTEJANO, P. R. R. As relações campo-cidade no Brasil do século XXI. Terra Livre, São Paulo, ano 19, v.2, n.21, p.25-39, jul./dez. 2003.

Reforma agrária, caos urbano, agronegócio e pandemia. Tamoios, São Gonçalo (RJ), ano 16, n. 1, p.32-38, mai. 2020. Especial COVID-19.

ALTIERI, M. A.; NICHOLLS, C. I. A agroecologia em tempo de Covid-19. Disponível em:< https://www.clacso.org/pt/a-agroecologia-nos-tempos-do-covid-19/>. Acesso em: 20 set. 2020.

APIB; AMAZON WATCH. Relatório Cumplicidade na destruição III. Como corporações globais contribuem para violações de direitos dos povos indígenas na Amazônia brasileira. 2020.

BOMBARDI, L. M. Coronavírus pode ter surgido do modelo predatório do agronegócio, diz estudo. Entrevista. Rede Brasil Atual, 04 abr. 2020. Disponível em: $<$ https://www.redebrasilatual.com.br/ambiente/2020/04/coronavirus-agronegocio modelo-predatorio/>. Acesso em: 20 abr. 2020.

CHAGAS, R. Agentes populares de Saúde em ação para uma periferia viva. Brasil de Fato, 03 ago. 2020. Disponível em: <https://www.brasildefato.com. br/2020/08/03/agentes-populares-de-saude-em-acao-para-uma-periferia-viva $>$. 
Acesso em: 29 out. 2020.

ETC GROUP. ¿Quién nos alimentará? La red campesina alimentaria o la cadena agroeindustrial. 3. Ed. ETC Group, 2017.

FERNNADES, B. M. Territórios da questão agrária: campesinato, reforma agrária e agronegócio. Reforma Agrária, v.34, n.2, p.77-93, jul./dez. 2007.

FERREIRA, J. 100 milhões de árvores: Conheça o plano nacional de plantio do MST. Movimento dos Trabalhadores Rurais Sem Terra, 7 fev. 2020. Disponível em: https://mst.org.br/2020/02/07/100-milhoes-de-arvores-conheca-o-plano-nacional-de-plantio-do-mst/. Acesso em: 28 out. 2020.

FUHRMANN, L. Acusados de desmatamento no Pantanal avançam também sobre Bolívia e Paraguai. De olho nos ruralistas, 20 out. 2020. Disponível em: https://deolhonosruralistas.com.br/2020/10/21/acusados-de-desmatamento-no-pantanal-avancam-tambem-sobre-bolivia-e-paraguai/. Acesso em: 25 out. 2020a.

. Gado, carvão, cana e soja estão por trás do desmatamento milionário no Pantanal. Brasil de Fato, 28 out. 2020. Disponível em: <https://www.brasildefato. com.br/2020/10/28/gado-carvao-cana-e-soja-estao-por-tras-do-desmatamento-milionario-no-pantanal>. Acesso em: 29 out. 2020b.

GIMENES, E. Movimentos sociais se unem contra a fome na abertura da semana nacional de alimentação. Brasil de Fato, 12 out. 2020. Disponível em: https:// www.brasildefato.com.br/2020/10/12/movimentos-sociais-se-unem-contra-fome-na-abertura-da-semana-nacional-da-alimentacao. Acesso em: 28 out. 2020.

GOULD, L. Ponto a ponto: conheça o plano de reforma agrária popular defendido pelo MST. Brasil de Fato, 15 jun. 2020. Disponível em: https://www.brasildefato. com.br/2020/06/15/ponto-a-ponto-conheca-o-plano-de-reforma-agraria-popular-defendido-pelo-mst. Acesso em: 05 jun. 2020.

HARVEY, D. Política anticapitalista em tempos de Covid-19. In: DAVIS, M. et al. Coronavírus e luta de classes. Terra sem amos: Brasil, 2020.

HOUTART, F. Dos bens comuns ao 'bem comum da humanidade'. Bruxelas/ Bélgica: Fundação Rosa Luxemburg, 2011. Versão em português: CONCEIÇÃO, R. L. C. (Trad.). in: Disponível em: info@rosalux-europa.info. Acesso em: 30 set. 2017. 
MATHEUS, F. A. Entrevistas e notas realizadas durante o Encontro Nacional de Mulheres do MST. Caderno de Campo, 2020. Não publicado.

MÉSZÁROS, I. O desafio e o fardo do tempo histórico. São Paulo: Boitempo, 2007.

MOVIMENTO DOS TRABALHADORES RURAIS SEM TERA. Programa Agrário do MST. Documento aprovado no VI Congresso do MST. São Paulo: MST, 2013.

PETERSEN, P.; LONDRES, F. Seminário regional sobre agroecologia na América Latina e Caribe. Agriculturas, v.12, n.3, 2015.

RAMOS FILHO, E. S. A reforma agrária como território da política e a reforma agrária de mercado como território da economia. In: FERNANDES, B. M.; RINCÓN, L. F.; KRETSCHMER, R. (Org.). La actualidad de la reforma agraria en America Latina y el Caribe. Buenos Aires; São Paulo: CLACSO; Fundação Perseu Abramo, 2018. Disponível em: http://www2.fct.unesp.br/nera/ltd/actualidad_reforma_2018.pdf.. Acesso em: 10 abr. 2020, p. 149-154.

SHAH, S. Contra pandemia, ecologia. Le Monde Diplomatique Brasil, ed. 152, 28 fev. 2020. Disponível em: https://diplomatique.org.br/contra-a-pandemia-ecologia/. Acesso em: 03 mar. 2020.

SZMRECSÁNYI, T. Expansão do agronegócio e ameaças à soberania alimentar: o problema dos biocombustíveis. Reforma Agrária, v.34, n.2, p.149-154, jul./dez. 2007.

THOMAZ JÚNIOR, A. Se camponês, se operário! Limites e desafios para a compreensão da classe trabalhadora no Brasil. Geografia e trabalho no século XXI, v.2, p. 135-170. 2006.

VÁSQUEZ, A. S. Filosofia da práxis. São Paulo: Expressão popular, 2007.

WALLACE, R. Pandemia e agronegócio: doenças infecciosas, capitalismo e ciência. São Paulo: Elefante \& Igra Kniga, 2020. 